\title{
Correction to: "in-vitro examination of the positive inotropic effect of caffeine and taurine, the two most frequent active ingredients of energy drinks"
}

R. Chaban*, A. Kornberger, N. Branski, K. Buschmann, N. Stumpf, A. Beiras-Fernandez and C. F. Vahl

\section{Correction to: BMC Cardiovascular Disorders}

(2017) 17:220

https://doi.org/10.1186/s12872-017-0625-z

Following publication of the original article [1], the authors of the above mentioned article would like to declare that this work includes results, which are part of the medical Thesis of the co-author: Ms. Nicola Branski.

Received: 25 January 2019 Accepted: 25 January 2019

Published online: 04 February 2019

\section{Reference}

1. Chaban, et al. BMC Cardiovascular Disorders. 2017;17:220. https://doi.org/10. 1186/s12872-017-0625-z 